\title{
Research on the Physical Education Teaching Reform in Colleges and Universities from the Perspective of Lifelong Physical Education
}

\author{
Hui Xiao, Yanlan Chen \\ Physical Culture Institute, Jiangxi Science and Technology Normal \\ University, Nanchang, Jiangxi, 33001
}

\begin{abstract}
Lifelong sports is considered the new century sports ideas, has become a consensus. College sports is the final stage of school sports, with the characteristics of convergence with social life, college students face from school education to social employment change, therefore, from the perspective of lifelong sports, college sports stage not only to solve learning problems, but also To solve the current and future use of the problem. This article discusses the guiding ideology of college PE reform in the 21st century from the expatiation of lifelong physical education, and provides useful reference for students to end the school sports learning stage to the society and establish lifelong sports concept. Keywords: physical education teaching reform, colleges and universities, lifelong physical education
\end{abstract}

\section{Introduction}

Lifelong physical education is a kind of ideological trend of modern sports. Its appearance and the emergence and development of the concept of lifelong education are closely related to the development of modern society. The concept of lifelong education that the significance of school education is limited to the stage of education, students in a variety of environments are able to independently self-learning and self-development ability. Therefore, the university physical education must take the lifelong education as the education guiding ideology, carries on the educational reform. With the establishment and 
development of China's market economic system, especially the development of modernized large-scale production, people's material and cultural life become increasingly rich, working time shortened, leisure time increased, the formation of weekends, sports culture life gradually become people's life. Indispensable content. School sports in the lifelong sport plays a "bearing" role, is an important part of lifelong education. College physical education is the highest level and the final stage of school physical education. It has the characteristics of strong connection with the future social life and serves as the foundation for college students from the school to the social environment. Today's college students is no longer a simple accumulation of knowledge, but should be moral, knowledge, physical, physical and mental health complex. We should attach importance to the late social effects of school sports, the purpose of the students lifelong physical education, so that after entering the community to play their own sports expertise and the theoretical knowledge, scientific and rational guidance of their physical exercise, to the physical and mental Health, so that they have plenty of energy into the work and life to make more contributions to the country. Therefore, we must firmly establish lifelong sports education ideas, to change the old concept of physical education for decades and specific implementation of the mistakes. Such as the level of primary and secondary schools is unclear, the content of teaching materials around the competitive sports repeated, boring; light theoretical study, heavy skills training; neglect lifelong benefit of students in sports science knowledge; teaching to teachers, students Passive learning as a supplement, the lack of a positive learning atmosphere and so on. Starting from the idea of lifelong education, we should pay attention to cultivate students 'sports consciousness and students' sports ability, and cultivate the habit of physical exercise consciously, laying a solid foundation for lifelong sports.

\section{Develop students' interest and habits in sports}

Interest is people's awareness of things and the tendency of consciousness in practice. Interest is generated on the basis of the needs of the human body, interest shown by the positive emotions will lead to behavior on a hobby activities, thus the formation of behavior. Sports interest refers to the mood of sports preferences. To cultivate students to participate in life-long physical exercise habits and ability, interest is the main condition for learning. When a student has a need for learning or participation in a sport, he or she will have some kind of sports interest and begin to approach, explore, and fulfill his or her needs through a series of learning or practical activities. Satisfied will produce a pleasant mood, and in the new needs of the drive, they began a new inquiry practice, so that sports interests continue to improve. In this, in the university physical education teaching, must carry on the reform in all directions, and in the future social sports conformity, the correct guidance, the training student voluntarily carries on the physical activity the ability and the custom. Sports habits in the cultivation of your persistence, and only perseverance in order to 
receive enhanced physical fitness, exercise awareness, emotional regulation, physical and mental effects of entertainment.

When students deal with various interpersonal relationships in life, there will be many contradictions caused by some psychological imbalance, resulting in discontent. These grievances need to vent places and opportunities, if the school can not provide such a place and opportunity for college students, it is easy to lead to various problems. The emotional transfer and spiritual input of sports provide a medium for college students to communicate and understand each other in the field of sports so as to promote the interconnection of groups and individuals. Such a situation will bring together a huge The spirit of the times and the undercurrent, to the school's stability, progress and development to add vitality. Therefore, in the university education reform, sports will be its unique features for the school progress fueled. In the fitness exercise, the physical and mental health of college students can be pleasure, feelings to vent, sports has become a modern society must be. In the fitness exercise, students really experience the fun of sports and the resulting sense of accomplishment, selfconfidence self-esteem self-improvement self-initiative, competition consciousness, self-emotional control ability is strengthened, is conducive to the normal development of individual personality psychology.

\section{Establishment of lifelong physical education curriculum system in colleges and universities}

Change old ideas, emancipate the mind, clear training objectives. Physical education is the basic way to carry out the sports goal and task. Physical education in colleges and universities in China has been changing from sports technology to strengthening physical fitness for many years. However, the actual teaching is changed or changed to technology. The reasons are various, but the main reason, Should be technology-centric old curriculum mischief. We should establish a new teaching mode of school physical education with lifelong sports as the guiding ideology. That is to say, we must abolish the traditional single physical education class in the organization form of physical education, boldly emancipate the mind, try to set up new educational mode, combine physical education, Education, recreation education, life education and athletic education should be carried out in physical education teaching so that students can really understand the significance and effect of participating in physical exercise, actively and effectively guide students to sports learning, stimulate students' interest in sports, The maximum to meet their desire to engage in physical exercise, so that students from the sports learning and exercise experience the fun. By reforming the teaching of physical education curriculum, students can master the knowledge and methods to enhance physical fitness and motor skills, cultivate the awareness and ability to enhance physical fitness, and promote students to take part in the exercise actively and independently., So that students in the university stage to learn the benefits of life-long sports and the 
corresponding theoretical knowledge, physical exercise to guide the scientific method of lifelong sports.

Reform teaching syllabus, improve teaching content, appropriate to enhance the number of sports theory. The revision and improvement of the outline textbook should be based on the goal of "strengthening students and educating people", and exercise and train students' physical and mental health as the main body. However, at present, the teaching material system, the curriculum, the structure of the course and the teaching mode of the college sports still emphasize on the teaching of the sports technology as the center, and the teaching mode of the college sports teaching, Too much from the perspective of sports technology, and emphasis on the external form of movement, the choice of the project most of the lack of lifelong benefits, far from being able to adapt to students after graduation life and work, sports awareness can not be consolidated, Therefore, it is necessary to set up a system of sports practical teaching materials which can enable students to carry out themselves after graduation and have high value of exercise, easy to learn, easy to practice, easy to use, and little benefit. Secondly, to cultivate college students 'sports consciousness is one of the important contents of college physical education. To enhance the students' sports consciousness, we must educate the students on the theory of physical education, increase the number of theoretical class hours, make the students understand the purpose and meaning of lifelong sports, Exercise and theoretical knowledge, in order to make life-long sport possible.

Improve teaching methods to improve students' interest in exercise. Interest is the most realistic and active component of learning motivation. It is the starting point of motivation cultivation, and learning interest will be carried out consciously. In order to improve students' interest in exercise and improve teaching quality, teachers should use practical, flexible and diverse teaching methods in teaching, so that students from passive participation to actively participate in, so as to cultivate the ability of students to spontaneous physical activity And habits. 4. Pay attention to individual differences. Sports is a kind of independent behavior of the students, the students have their own personality and awareness of this, are willing to exercise in the exercise of their talent and athletic ability to achieve the needs of respect and self-realization needs. Therefore, teachers should pay attention to individual differences, for the needs and interests of students, the use of individualized teaching and personalized teaching methods, so that each student has a positive emotional experience, so as to effectively promote the consolidation of student interest in sports and development, with a view to To achieve the best teaching results. 5. Gradually modify the assessment content and assessment criteria. The formation of lifelong sports consciousness of students is inseparable from the "success" experience in physical education teaching and sports activities. This "success" is not only reflected in the sports technology, skills improvement, but also should be reflected in the physical education and physical exercise, students master the physical knowledge, physical health and physical fitness, overcome difficulties, progress, The enhancement, as well as the physical activity itself gives the student the good emotion experience and so on. Therefore, teaching evaluation and assessment, 
not only to consider the existing sports skills of students, students should also consider the degree of effort, and students in the classroom teaching in the degree of participation, synergies and other aspects of comprehensive evaluation, so that Teaching evaluation really play to improve the role of each student learning initiative.

The combination of human knowledge, health, health education and recreation sports, traditional sports, family sports and some sports content, theory and practice, so that students before entering the society, not only master a certain amount of health knowledge, exercise theory and Often engaged in the basic methods of physical exercise, to develop a good habit of physical exercise, but also enhance the sense of lifelong sports that students, after entering the community often participate in sports activities to lay the foundation. The focus of teaching, from the syllabus to athletics as the main content to fitness, entertainment, health and other sports-focused teaching content up, strengthen the teaching of sports appreciation courses, the infinite charm of competitive sports to attract students, so that Students to sports stars for the idol, to participate in sports activities for pride, consciously exercise their own, and develop habits. This imperceptible factor is very important, so that the students understanding of the quality of physical changes in the future physical education should guide students in this inner passion and motivation, will make teaching more with less, so the teaching of theory should be On the teaching process in the first place, the theory to guide practice, theory with practice is the truth.

\section{Conclusion}

The selection and organization of the content of physical education should take the needs of social development as the starting point, not only to meet the needs of social development, but also from the social development of the characteristics of the times. At present, China is carrying on the quality education as the theme of school sports reform. In this background, the school sports presents a fitness, humanities, basic, entertaining, competitive, subjective, selective, national and open, and other characteristics of the times. The selection and organization of the contents of physical education should pay full attention to the quality of education in this era background and school sports characteristics of the times.

\section{References}

[1] Deng Qiang. Examining the Reform and Development of College Physical Education from the Perspective of Lifelong Sports Thought. Journal of Sports Articles and Technology. , 55(12), pp.68-70, 2011

[2] Fan Huaike, Peng Dan.Study on the significance and value of lifelong sports thought. Sports. 8 (5), pp.87-91, 2013

[3] Wang Yanchao. Talking about the convergence of physical education curriculum and lifelong sports. Sports. 12(10), pp. 18- 20, 2012 
[4] Song Wei. Analysis of the formation of students' lifelong sports ideology. Science and Technology Information. 9(6), pp.58- 61, 2011

[5] Li Junheng.Physical education under the concept of lifelong physical education teacher training mechanism. China Adult Education. 8(4), pp.85-87, 2014 